\title{
TRAS LAS HUELLAS DEL CURRICULUM
}

Prof. Silvia Morelli (Universidad Nacional de La Plata) (Universidad Nacional de Rosario)

\section{"Alternativas metodológicas de intervención curricular en la Educación Superior". \\ De Rita Angulo y Bertha Orozco (coordinadoras). \\ Plaza y Valdéz Editores. México, 2007. 366 páginas.}

El libro pertenece a la colección "Educación, Debates e Imaginario Social", dirigida por Alicia de Alba. Esta cuenta con tres proyectos especificos; Educación Ambiental, Teoría y Educación y Curriculum Siglo XXI. Es a este último proyecto que pertenece este libro.

Este texto, coordinado por Rita Angulo y Bertha Orozco, resulta de una tarea colaborativa en la que intervienen estudiosos y actores del curriculum de diferentes universidades mexicanas y una extranjera como la Universidad Nacional Autónoma de México, la Universidad Autónoma de San Luis Potosí, Universidad Autónoma de Zacatecas, UAM Xochimilco, Universidad Veracruzana, Universidad Autónoma de Guerrero, Universidad Autónoma de Chapingo y la Universidad de Buenaventura (Colombia).

Las reflexiones y aportes que contiene sobre el curriculum universitario devienen un complejo entramado de una historia que no se fue elaborando de manera lineal. Por un lado es el producto de décadas de trabajo y producción en torno al curriculum y a la educación que comenzó de la mano de Alicia, hace 25 años. Por el otro es el resultado especifico de las producciones del Seminario de Investigación Curriculum Siglo XXI cuya coordinadora académica es Bertha Orozco.

Esta producción de trazos compartidos es una buena excusa para escribir sobre las alternativas metodológicas en el curriculum universitario del siglo XXI. Tiempo presente dislocado que reclama la re-estructuración en la búsqueda de otros horizontes.

$$
-303-
$$


La composición compleja de esta trama está sostenida por dos categorías que juegan un papel clave a lo largo de la producción, ellas son: Alternativas Metodológicas e Intervención Curricular

La Intervención Curricular es considerada aquí como un modo de dar respuestas académicas que construyen conocimiento situacional y permite la elaboración de categorias in situ. Son pensadas para la construcción de categorias in situ, creando conciencia social. Implica el reconocimiento de un espacio, ya sea institucional, teórico, político o metodológico en el que el curriculum interviene.

Las Alternativas Metodológicas son enunciadas en plural, atendiendo a las singularidades de los procesos de cada institución y con un sentido amplio de aquello que, los que pertenecemos al campo del curriculum y la didáctica, entendemos por metodología. Es precisamente aqui donde se encuentra un indicio importante para la construcción de diseños curriculares recurriendo a instancias de elaboración de discursos, haciendo intervenir los procesos de debate y de reflexión que denotan que la construcción metodológica está presente en un diseño curricular.

Significa que no se puede pensar el curriculum sin ese proceso político de comunicación y tensiones considerados en la determinación curricular y que sin duda trae implícito un abordaje metodológico, que trazará itinerarios para el diseño y para las prácticas.

En la actualidad, pretender dar cuenta a qué llamamos curriculum es una tarea mucho más compleja de lo que demostró ser en el siglo $X X$, cuando en su corta historia ya se asumia en una ambigüedad conceptual. Es imperiosa la tarea de volver sobre lo que entendemos por él puesto que las perspectivas tecnicistas, prácticas y críticas ya no son suficientes para dar cuenta de la epistemologia de este objeto que navega entre la complejidad y la incertidumbre. El presente libro demuestra comprometerse con este emprendimiento

Sus primeros capítulos dan cuenta de ello, artículos escritos por de Alba, Diaz Villa, Nieto Caraveo y Orozco arriesgan apreciaciones teóricas para reconceptualizar al curriculum, a partir de los procesos de reforma. En el caso de la primera de estas autoras, ofrece un contexto de análisis donde el cambio es entendido como proyecto social, no siempre logrado, replanteándose el vínculo curriculum - sociedad ante la crisis social generalizada. En un entorno globalizado y complejo (al decir de Morin) se preocupa de las inequidades socio - económicas que configuran el mapa poblacional en el que interviene la educación, como un acto de reivindicación de igualdad social.
El segundo de los autores se refiere a las tensiones generadas en las instituciones de educación superior, cuando éstas deciden procesos de reformas. Es importante el aporte teórico que realiza este autor al concepto de tensión analizado en dos manifestaciones: la que se plantea entre la institución educativa y las fuerzas productivas y la que se produce entre los académicos de una institución. Tensión y reforma son dos categorias que se analizan en el marco de la educación superior y que ayudan a vislumbrar focos conflictivos en los cambios curriculares.

La tercera, Nieto Caraveo ofrece elementos de análisis para pensar cambios curriculares: la participación, la deliberación y la investigación. Este articulo ayuda a definir modos de trabajo que encauzan con coherencia la tarea de diseño de un nuevo plan de estudios. Lo interesante de esta producción es que considera que la elaboración de una propuesta curricular está relacionada con procesos y bases de organización que mantengan la dinámica de reflexión, evaluación y cambio curricular de forma colegiada.

El cuarto artículo de esta serie, el que propone Orozco, una de las coordinadoras del libro, se refiere al asesor en curriculum. Una acertada propuesta viene a plantear la construcción de este rol tras la consideración del encuentro del asesor con los actores como colectivo docente y la capacidad de escucha de éste para respaldar una intervención adecuada y prudente.

El relato de distintas experiencias se hace presente a partir de los capitulos que siguen y permiten configurar una trama de acontecimientos que tuvieron lugar en distintas carreras de diferentes universidades. Trama que denota singularidad y es en ésta misma donde se construyen los aportes a las alternativas metodológicas para la construcción de cambios curriculares. Pero en el rescate de estas experiencias de cambio curricular hay marcas que permiten reconstruir este discurso en la arena socio-cultural de las prácticas.

Los capítulos cinco, seis y siete, escritos por (1) Martínez Delgado, (2) Ysunza - González de León - Torre y (3) Lagos Ramón - Martínez Aguilar - Torres Flores dan cuenta de una identidad grupal y de trabajo con el otro. Asi se escribe destacando la experiencia vicaria, colectivo docente, experiencia colectiva, voces de los actores donde el núcleo central de las reformas curriculares estuvo puesto en el rescate de los sujetos como protagonistas de estas alternativas metodológicas.

Continúan los capitulos: ocho, nueve, diez y once escritos por Gallardo Gutiérrez, Angulo Villanueva (la otra coordinadora de este libro), Bravo Mercado y Ayala que atienden a diferentes problemas que se hacen pre- 
sentes con sus propias intensidades en el curriculum como lo son la diversidad cultural, étnica y lingüística, los contenidos del curriculum, la contextualización en el proyecto institucional y la formación docente.

La amplitud de esta obra denota su acierto para pensar en curriculum en el siglo XXI. Esta tarea de recomposición de un campo tan joven y controvertido como lo es el curricular incluye aspectos conceptúales y epistemológicos referidos al curriculum junto al relato de experiencias puestas en práctica por diferentes grupos de académicos entre las que se cruzan y destacan algunos de los problemas emergentes para el campo curricular.

Tanto unas como otras permiten seguir pensando actuales líneas de abordaje que ofrecen nuevos horizontes al curriculum en los comienzos de este siglo. Esta obra ocupa el lugar de la promesa de saldar una importante deuda educativa; la de arrojar cierta claridad provisoria hacia la construcción de este campo con autonomia de las corrientes hegemónicas y de cara a los contextos educativos de Latinoamérica.

Una mirada hacia el curriculum desde una perspectiva institucionalizada ayuda a comprender la encrucijada donde se eslabonan semiosis normativas, la necesidad de organización de la cultura académica, con las singularidades entre las que se encuentran las culturas institucionales y los sujetos de la determinación curricular. 